\title{
COLABORAÇÃO/COOPERAÇÃO ESCRITA VIA INTERNET: QUESTÕES TEÓRICO-PRÁTICAS PARA INOVAR PRÁTICAS DE ESCRITA NA ESCOLA
}

\section{WRITTEN COLLABORATION/COOPERATION VIA INTERNET: THEORETICAL-PRACTICAL ISSUES TO INNOVATE WRITING PRACTICES AT SCHOOL}

\section{Petrilson Alan Pinheiro*}

RESUMO: O objetivo deste artigo é realizar uma discussão teórica sobre a questão da produção textual colaborativa (incluindo os conceitos de colaboração e cooperação) no contexto sócio-histórico atual. Essa discussão teórica se apoia em análises de dados gerados com um grupo de alunos de uma escola pública de Ensino Médio na produção de textos para um jornal digital escolar, cuja intenção é mostrar como práticas de escrita se constituem ao longo de um processo colaborativo de escrita e apresentar uma proposta de conceituação do que estou chamando de 'práticas colaborativas de escrita'. PALAVRAS-CHAVE: Colaboração/cooperação. Práticas colaborativas de escrita. Internet. Escola.

ABSTRACT: The objective of this paper is to carry out a theoretical discussion about collaborative text production (including the concepts of collaboration and coordination) in the current sociohistorical context. Such theoretical discussion is also based upon analyses of empirical data generated with a group of students of a public High School in the text production for a digital school

\footnotetext{
Professor Doutor do Departamento de Linguística Aplicada do Instituto de Estudos da Linguagem da UNICAMP. E-mail: petrilsonpinheiro@yahoo. com.br.
} 
newspaper, whose intention is to show how writing practices are constituted along a collaborative writing practices process and to present a conceptualization proposal of what I am calling 'collaborative writing practices'.

KEYWORDS: Collaboration/cooperation. Collaborative writing practices. Internet, School. 


\section{COLABORAÇÃO/COOPERAÇÃO ESCRITA VIA INTERNET: QUESTÕES TEÓRICO-PRÁTICAS PARA INOVAR PRÁTICAS DE ESCRITA NA ESCOLA}

\section{INTRODUÇÃO}

Na era atual da (trans)informação', a palavra "colaboração" parece ter ser tornado uma das buzzwords em diversas áreas do conhecimento, sobretudo após o advento da Web 2.0. De fato, com a Web 2.0, houve, ipso facto, uma reconfiguração no campo da comunicação, tencionando o modelo vigente do broadcast (sistema de transmissão de informação em larga escala), em que apenas um seria responsável pela comunicação. Os usuários da Internet não apenas pesquisam para encontrar informação; eles também criam e publicam conteúdos, gerando, por conseguinte, uma mudança no modelo de comunicação, que passou do formato "um-para-muitos" para o "muitos-para-muitos".

Esse novo modus operandi fez com que a rede passasse a oferecer um novo ambiente, não apenas para leitura, mas para a escrita. Nesse sentido,

1 Estou chamando de "era da (trans)informação" o momento sócio-histórico atual, em que a informação não apenas circula em uma rede global (rede mundial de computadores), mas também sofre metamorfoses ao se tornar cada vez mais fluida e multifacetada, num processo de retroalimentação contínuo que transforma a si mesma. 
pode-se afirmar que cada tecnologia oportuniza um espaço diferente de escrita, acompanhando a evolução dos suportes. Um exemplo particularmente interessante dos efeitos da Web 2.0 é a Wikipedia, um dos dez sites mais visitados do mundo, que se caracteriza como uma espécie de enciclopédia online para a qual qualquer usuário pode colaborar com um texto². A Wikipedia é, de fato, um bom exemplo de como sites de fácil utilização encorajam usuários a submeter os seus próprios materiais para a rede, mostrando que, se a Web 1.0 era um meio de leitura, a Web 2.0 se tornou um meio de leitura e escrita. Contudo, quando se trata de produção colaborativa de escrita, consideram-se todas as práticas de escrita na Web 2.0 como, de fato, colaborativas, ou apenas a escrita em si seria colaborativa? Nesse caso, há diferença entre escrita colaborativa (doravante, EC) e práticas colaborativas de escrita (doravante, $\mathrm{PCE})$ ? Se realmente há diferença entre os dois termos, não seria necessário, por sua vez, repensar as noções de colaboração e cooperação, uma vez que se encontram imbricadas em ambos os termos?

Em um artigo publicado recentemente (PINHEIRO, 2011a), tematizei a questão da EC no contexto escolar, por meio de dados empíricos gerados em uma escola pública. No entanto, embora tenha trazido reflexões acerca do processo colaborativo de escrita e elaborado dispositivos teórico-analíticos para a análise dos dados, não tratei especificamente da diferença entre a EC e as PCE. Neste artigo, porém, o objetivo é o de trazer à tona a discussão sobre ambos os termos, formulando, assim, um conceito próprio de colaboração, com base nos mesmos dados empíricos gerados para o artigo anterior supracitado. Todavia, diferentemente do primeiro, o foco do presente artigo é realizar uma discussão teórica, apoiando-me em um exemplo empírico que ajudará a corroborar a proposta de uma melhor compreensão e conceituação do que são PCE. Para tanto, parto de uma discussão importante e controversa acerca dos conceitos de colaboração e cooperação no campo de ensino-aprendizagem, para, então, tratar dos termos EC e PCE e mostrar,

2 Apesar de estender a possibilidade de publicação de texto a qualquer usuário, a Wikipedia estipula determinadas regras e princípios para submissão, que, se não forem seguidos pelo usuário, este pode ter seu texto retirado da página da enciclopédia (para informações sobre as regras e princípios para contribuições de textos, ver http://pt.wikipedia.org/wiki/ Ajuda:Guia_de_edi\%C3\%A7\%C3\%A3o/Como_come\%C3\%A7ar_uma_p\%C3\%A1gia). 
com base em análises de produções textuais colaborativas no contexto escolar, o quanto pode ser interessante e enriquecedor para o ensino de línguas repensar e inovar no ensino de produção textual na escola.

\section{COLABORAÇÃO: UMA DISCUSSÃO CONCEITUAL}

No contexto de ensino-aprendizagem, nas duas últimas décadas, tem-se, de fato, discutido consideravelmente acerca da colaboração (COLLIS, 1993; WINER; RAY, 1994; MACAULAY; GONZALES, 1996; GROSZ, 1996; PANITZ, 1996; ALLEN et al.,1997; HILTZ; BENBUNAN-FICH, 1997; LAROCQUE; FAUCON, 1997; BRNA, 1998; HENRI; LUNDGREN-CAYOL, 2001; COMEAUX, 2002; MCINNERNEY; ROBERTS, 2004; BARKLEY et al., 2005; LIBERALLI, 2007; IBIAPINA, 2008; MAGALHÃES; FIDALGO, 2010) entre outros.

Para Collis (1993), a colaboração, seja no contexto de ensino e aprendizagem ou não, constitui-se por meio de um processo de produção compartilhada: dois ou mais sujeitos, com habilidades complementares, interagem para criar um conhecimento compartilhado que nenhum deles tinha previamente ou poderia obter por conta própria. Nesse caso, a colaboração criaria um significado compartilhado sobre um processo, um produto ou um evento. Isso significa que, ao trabalharem em grupo, os sujeitos podem produzir melhores resultados do que se atuassem individualmente. Num trabalho colaborativo, portanto, ocorre, segundo o autor, a complementaridade de capacidades, de conhecimentos, de esforços individuais, de opiniões e pontos de vista, além de uma capacidade maior para gerar alternativas mais viáveis para a resolução de problemas.

Com efeito, a visão de que o trabalho em grupo pode ser mais produtivo do que o trabalho individual parece ser um ponto pacífico entre os autores supracitados e, seguramente, entre todos os demais autores que lidam com a questão. Contudo, no que diz respeito ao contexto de ensino-aprendizagem, é válido trazer à tona a discussão recente que se tem feito acerca dos termos 'colaboração' e 'cooperação', que, em geral, são tomados como conceitos com diferentes perspectivas e técnicas, ou como parte de um continuum de es- 
tratégias baseadas em aprendizagem coletiva, partindo da mais estruturada (cooperação) para a menos estruturada (colaboração).

Macaulay \& Gonzales (1996) e Comeaux (2002) postulam que a cooperação, contrariamente à colaboração, pressupõe uma tarefa distribuída entre os vários elementos do grupo de trabalho, cuja ênfase recai na realização da tarefa individualmente, baseada em subtarefas destinadas especificamente para cada integrante, sem que haja necessariamente um encontro entre elas. O trabalho colaborativo, por sua vez, não se caracteriza, segundo os autores, pela soma ou justaposição dos trabalhos individuais, por isso, é necessária uma maior cumplicidade entre os participantes do grupo para o estabelecimento de objetivos comuns e das atividades a serem realizadas. Os autores ainda apontam que a cooperação é realizada "através da divisão do trabalho entre os participantes, como uma atividade em que cada pessoa é responsável por uma porção da solução do problema”, enquanto a colaboração envolve "o empenho mútuo dos participantes em um esforço coordenado para solucionarem juntos os problemas".

Panitz (1996) e Henri \& Lundgren-Cayol (2001), por sua vez, ponderam que, na cooperação, existe uma organização maior do grupo, com um maior enfoque no controle da situação por parte de alguém (um chefe ou professor, por exemplo). A colaboração, por sua vez, implica em um processo mais aberto e criativo, em que os integrantes do grupo interagem para atingir um objetivo comum. Panitz (1996) explica que a cooperação é mais estruturada porque o professor teria o total controle da atividade proposta, uma vez que é ele quem fornece os materiais de suporte à sua realização; aos alunos, caberia realizar, então, a atividade e apresentar os resultados para todos (professor e colegas). Nesse sentido, segundo o mesmo autor, a aprendizagem cooperativa, por ter sua base em uma série de processos definidos pelo professor para auxiliar os aprendizes a interagirem com a finalidade de alcançar um objetivo em comum, seria mais centrada no professor, enquanto que a aprendizagem colaborativa seria mais centrada no aluno.

Essa posição é também defendida por McInnerney e Roberts (2004), para os quais o termo aprendizagem colaborativa é mais apropriado para ser usado para referenciar as técnicas que enfatizam a interação aluno-aluno, enquanto que o termo aprendizagem cooperativa deveria ser usado para 
designar as situações em que os alunos devem trabalhar em pequenos grupos sob a orientação do professor. A esse respeito, Grosz (1996) vai ainda mais longe. Por também considerar que a colaboração se dá muito mais na relação aluno-aluno, o autor pondera que o termo aprendizagem cooperativa deve ser usado para se referir a uma aprendizagem coletiva nos Ensinos Fundamental e Médio, enquanto a aprendizagem colaborativa seria mais adequada na Educação Superior.

Para Winer \& Ray (1994), a colaboração, além de ser mais aberta e criativa, o que a torna, por conseguinte mais autônoma, é também um processo em que há maior relacionamento entre os participantes e um grau de comprometimento maior com o trabalho se comparada com a cooperação. Segundo os autores, a relação entre as duas perspectivas (cooperação e colaboração) se caracteriza também como um continuum, em que o trabalho cooperativo evolui gradativamente até se tornar um trabalho colaborativo.

A distinção entre cooperação e colaboração é também enfatizada por Larocque \& Faucon (1997), ao apontarem que na cooperação ocorre uma ajuda mútua na execução de tarefas que nem sempre resultam de decisões conjuntas dos membros do grupo, podendo, inclusive, haver relações desiguais e hierárquicas entre os participantes. Na colaboração, por sua vez, o trabalho conjunto prevalece, por meio de apoio mútuo e definição coletiva de objetivos comuns. Desse modo, segundo os autores, na colaboração todos trabalham em conjunto e, por isso, as ações não são hierárquicas, mas são assumidas e realizadas através de um esforço coordenado e negociado, a fim de alcançarem um objetivo comum. Essa diferença é reforçada por Ibiapina (2008:18), ao afirmar que:

[...] Colaboração não significa cooperação, tampouco participação, significa oportunidade igual e negociação de responsabilidades, em que os partícipes têm voz e vez [...] geradas por meio de mútua concordância e de relações mais igualitárias e democráticas voltadas para o desenvolvimento de novos conhecimentos, novas compreensões e possibilidades de ação. 
Contudo, mesmo considerando pertinentes as características que diferenciam os dois termos (cooperação e colaboração), é possível notar que algumas definições apresentadas são questionáveis. Primeiramente, ao tomar os termos do ponto de vista etimológico, percebe-se que ambos se apresentam como sinônimos, conforme aponta o Dicionário Houaiss da Língua Portuguesa (versão eletrônica em CD-ROM, 2001 s/p):

'Cooperar', do latim "cooperor, aris, atus sum, ari - colaborar, trabalhar com outro(s) -, significa atuar, juntamente com outros, para um mesmo fim; contribuir com trabalho, esforços, auxílio; colaborar;

'Colaborar', por sua vez, do latim collaboro, as, avi, atum, are - trabalhar de comum acordo -, significa trabalhar com uma ou mais pessoas numa obra; cooperar.

Alguns autores, todavia, poderiam questionar a sinonímia entre cooperação e colaboração, baseada exclusivamente no critério (apriorístico) etimológico dos termos. No entanto, é preciso também considerar que todo trabalho colaborativo depende, em algum momento, da cooperação entre os membros de uma equipe. Assim, a colaboração e, por extensão, a cooperação são um empenho mútuo por um esforço coletivo para que um determinado grupo solucione conjuntamente um problema. Isso explica o fato de muitas vezes não ser possível dissociar a colaboração de algumas formas de cooperação. Por exemplo, mesmo em uma divisão de trabalho considerada "perfeita", típica de um trabalho cooperativo, os agentes envolvidos, em geral, têm, em algum momento do trabalho, que colaborar uns com os outros para reunir os resultados em um conjunto único. Por outro lado, em todo trabalho colaborativo, há sempre momentos de trabalho individual, quando, por exemplo, os membros de uma equipe estão realizando algumas das subtarefas do grupo por eles próprios (pensando ou escrevendo rascunhos no papel ou no computador etc.).

Outro ponto importante a ser considerado diz respeito ao papel dos participantes na colaboração. $O$ fato de a colaboração apresentar, segundo Ibiapina (2008), relações mais igualitárias e democráticas não significa que não 
possa haver liderança e, de uma certa forma, até assimetrias na interação. Em alguns casos, atividades colaborativas podem, inclusive, atingir melhores resultados quando um dos agentes desempenha um papel diferenciado, como o de facilitador no processo colaborativo, por exemplo. Por isso, sugestões, como a de Grosz (1996), que preconizam que o termo aprendizagem cooperativa deva ser usado para se referir a uma aprendizagem coletiva nos Ensinos Fundamental e Médio, enquanto a aprendizagem colaborativa, na Educação Superior, parecem pouco sensatas, visto que não levam em consideração os contextos específicos nos quais as atividades (cooperativa e colaborativa) são produzidas.

Destarte, mesmo reconhecendo que a cooperação e a colaboração apresentam certas diferenças no que diz respeito aos seus modos de funcionamento, a perspectiva que defendo neste artigo é a de que a colaboração se constitui a partir de um trabalho conjunto mais amplo, cujo processo envolve também a própria cooperação. Por isso, diferentemente das visões que enxergam ambos os termos como antagônicos, que se excluem mutuamente, vejo-os muito mais como partes complementares de um processo maior de trabalho coletivo (processo colaborativo), cujo nível de relacionamento entre os participantes e o grau de comprometimento com o trabalho podem aumentar ou diminuir, a depender das condições nas quais o trabalho em grupo ocorre. Nesse sentido, um grupo, por exemplo, pode se reunir (presencialmente ou online) para discutir sobre a elaboração de um dado documento e determinar, então, que cada membro da equipe se responsabilize por uma parte do documento, conforme é possível notar a posteriori neste artigo, com base nos dados empíricos gerados (ver seção 4). Tal concepção, portanto, atribui à colaboração uma complexidade maior, porquanto toma também a cooperação como uma das atividades necessárias de seu processo, sejam elas mais ou menos estruturadas.

Assim, penso que o trabalho colaborativo pode envolver uma justaposição de trabalhos individuais, típicos de trabalhos cooperativos, porém com a cumplicidade entre os participantes do grupo, que estabelecem, para esses trabalhos individuais, objetivos comuns que atendam às necessidades do grupo. Nesse sentido, o trabalho colaborativo se constitui a partir de um quadro de interações do grupo, no qual se compartilham descobertas, busca- 
-se uma compreensão mutua da situação, negociam-se os sentidos a serem atribuídos ao trabalho, bem como se validam novos saberes construídos.

É possível, portanto, afirmar que a colaboração é, antes de tudo, um empreendimento ativo e social, que possui duas forças de impulsão inter-relacionadas: o grupo, como agente de apoio individual, e o participante, cujo envolvimento para colaborar repousa no seu interesse em partilhar com o grupo a realização de tarefas.

Desse modo, pode-se dizer que, dado o seu caráter social, a colaboração tem como base outros conceitos, como socialização e confiança, identidade e coesão grupal, motivação e envolvimento ativo na participação. Isso é particularmente importante para a produção do jornal digital escolar (ver seção 4), por exemplo, uma vez que, nesse tipo de atividade, a colaboração está intrinsecamente relacionada à produção escrita realizada por meio da interação e do trabalho articulado entre os sujeitos envolvidos (os(as) alunos(as) participantes), e não por meio do simples aglomerado de pessoas que trabalham apenas individualmente. Na seção seguinte, passo a tratar de um tipo específico de colaboração que lida com a produção textual: o que chamo neste estudo de PCE.

\section{PCE: UM OLHAR PARA A PRODUÇÃO ESCRITA COMO UM PROCESSO DE TRABALHO EM CONJUNTO}

Nesta seção, procuro fazer uma discussão do que estou chamando neste artigo de PCE. Nesse sentido, para entender as PCE com um processo de trabalho de escrita em conjunto, é necessário, antes de tudo, discutir alguns pontos que considero primordiais: primeiramente, começo a discussão com o motivo pelo qual faço uso específico da expressão "Práticas Colaborativas de Escrita" (PCE) e não do termo normalmente usado "Práticas de Escrita Colaborativa" - tradução do inglês ("Collaborative Writing Practices"), conforme se tem observado em diversos trabalhos publicados nos últimos anos (HORTON et al.,1991; MERCER, 1996; ALLEN et al.,1997; LOWRY; NUNAMAKER JR., 2003; LOWRY; NUNAMAKER JR, 2004; STAHL; HESSE, 2006; SCHELLENS et al., 2007; STEGMANN et al., 2007) entre outros. 
Com efeito, ambas as expressões não são tomadas neste artigo como equivalentes. Nesse sentido, pode-se dizer que, a partir da internet, as discussões acerca da 'escrita colaborativa' (EC) têm se centrado ou no uso de determinados aplicativos, tais como Collaboratus, Grove, Sasse, Slashdot, Quilt, Alliance e o Equitext, que apóiam a "Escrita Colaborativa Distribuída Baseada na Internet" (Internet-based distributed Collaborative Writing), ou na elaboração coletiva de textos para sites da internet, blogs e wikis. Particularmente em relação a este último caso, pode-se mencionar a Wikipedia, um exemplo de EC, em que qualquer usuário pode submeter lexias para a construção de uma imensa enciplopédia coletiva online.

Todavia, ao fazer uso da expressão "Práticas Colaborativas de Escrita" (PCE), esta assume um significado específico neste trabalho. Isso se justifica em função de já considerar a prática, anterior à própria escrita, como colaborativa. Ao comparar, por exemplo, o trabalho de elaboração das lexias da Wikipedia com a produção das matérias do jornal de um grupo de alunos(as) (ver seção 4), nota-se que, no primeiro caso, a escrita é considerada colaborativa (PCE) apenas porque o produto final (as lexias postadas na enciclopédia online) se constitui por meio da contribuição de diferentes usuários, sem que, necessariamente, eles se reúnam para a elaboração das lexias, que podem ser feitas, inclusive, individualmente. Em outras palavras, a questão que levanto aqui é a de que a EC não pressupõe, necessariamente, a colaboração ao longo de seu processo, mas, tão somente, no resultado final. Aliás, a própria Wikipedia, ao definir EC, afirma que o termo se refere a alguns "projetos cujos textos são criados por um conjunto de pessoas (de modo colaborativo). Alguns projetos são supervisionados por um editor ou um time editorial, mas muitos crescem sem orientação específica"’.

Por outro lado, a produção das matérias do jornal dos(as) alunos(os) envolve um conjunto de práticas (colaborativas e cooperativas) ao longo de um processo, cujo início é a discussão sobre as matérias a serem produzidas e o término é a publicação das matérias no jornal online (ver seção seguinte). Nesse caso, pode-se dizer, portanto, que a colaboração entre os participantes

3 Fonte: http://pt.wikipedia.org/wiki/Escrita_colaborativa. Acesso em: 29 nov. 2009. 
já se faz presente antes mesmo da própria produção textual, o que atribui o caráter colaborativo mais às práticas (discussão sobre os assuntos das matérias e elaboração de esboços via conversa instantânea e correio eletrônico) do que à própria escrita em si, justificando-se, assim, o uso do termo "Práticas colaborativas de escrita" (PCE).

É possível também indagar que, na concepção que adoto de PCE - como processo colaborativo de construção de sentidos, passa-se a se centrar na inter-relação entre os participantes, o que envolve a mediação entre pessoas para a construção conjunta de um determinado objeto. Portanto, pode-se dizer que as PCE são entendidas neste estudo com base em duas características precípuas: como práticas que sempre envolvem um processo de desenvolvimento da escrita; e que sempre envolvem, ainda que não seja durante todo o seu processo, a participação de duas ou mais pessoas.

É preciso também apontar que, ao fazer uso do termo 'prática', estou, do mesmo modo, assumindo o conceito de prática consistente com aquele subjacente à argumentação de Wenger (1998: 47), ou seja, como "prática social". Segundo o autor:

O conceito de prática se refere a um fazer [...] mas a um fazer num contexto histórico e social que dá estrutura e significado ao que se faz. Neste sentido, prática é sempre prática social. [...] o conceito de prática salienta o caráter social e negociado tanto do explícito como do tácito das nossas vidas.

Percebe-se, pois, que a noção de prática não se restringe ao ato puro e simples de "fazer" alguma coisa; envolve algo mais amplo e dinâmico que, pela sua natureza social, intervém na definição de comunidades sociais de vários tipos. Em outras palavras, a prática social está inerentemente ligada à existência (ou à emergência) de comunidades ou conjuntos de pessoas que se reconhecem mutuamente como associadas a um conjunto de "fazeres".

Nesse caso, o conceito de prática social assume uma perspectiva sócio-histórica, que envolve, portanto, um processo mais amplo através do qual os sujeitos produzem e reproduzem as condições (materiais e simbólicas) e 
relações sociais que possibilitam sua existência. Nessa perspectiva, a prática social tem como ponto central exatamente a relação entre o cotidiano e o não-cotidiano, bem como a relação entre a experiência de cada um e as experiências do conjunto da sociedade, acumuladas ao longo de sua história.

Deve-se ainda dizer que as PCE, embora pareçam ser recentes, já estavam presentes nos primeiros trabalhos de escrita que sucederam à invenção da imprensa tipográfica. Chartier (2002), ao tratar do processo de produção e recepção dos textos no século XVII, aponta como alguns trabalhos literários já retomavam tais processos e os aplicavam às técnicas, máquinas e pessoas envolvidas na produção de "textos como formas escritas". O autor expõe, então, que escritores consagrados da época como Cervantes, Paredes e Moxon já demonstravam uma grande preocupação com os trabalhos do tipógrafo e do revisor no processo colaborativo de produção escrita. A esse respeito, Chartier (2002: 37) assevera que:

A produção do texto supõe diferentes etapas, diferentes técnicas, diferentes operações humanas. Entre o gênio do autor e a aptidão do leitor, como escreveu Moxon, uma multiplicidade de operações define o processo de publicação como um processo colaborativo, no qual a materialidade do texto e a textualidade do objeto não podem ser separadas.

Contudo, mesmo reconhecendo que as PCE já seriam, em alguns casos, multisseculares, todo o trabalho em conjunto que resultava em textos colaborativos sempre fora historicamente negligenciado em função da "autoridade do autor" e do caráter individual(ista) atribuídos às obras. Com efeito, parece que, só recentemente, o trabalho colaborativo de escrita vem sendo, de fato, legitimado, com a Web 2.0. Nesse sentido, Lowry et al. (2004) apontam que as PCE se constituem como práticas sociais que têm ganhado cada vez mais força, pois, ao mesmo tempo em que o processo de globalização aumenta a necessidade de desenvolver atividades colaborativas, em especial no campo dos negócios, a internet, com todos os seus recursos tecnológicos, possibilita esse trabalho colaborativo. Não é por acaso que pesquisadores 
de diferentes áreas do conhecimento, sobretudo das áreas tecnológicas ${ }^{4}$ (administração, marketing, engenharia, ciências e tecnologias da computação, midialogia, educação etc.), muitas vezes trabalhando a partir de perspectivas interdisciplinares, têm focalizado cada vez mais a questão das PCE.

Apesar de enfoques e posicionamentos teóricos diferentes ${ }^{5}$, muitos desses pesquisadores têm chamado a atenção para o caráter sócio-cultural no processo de construção de PCE. Dentro dessa perspectiva, Lowry et al. (2004:71) asseveram que as PCE são, antes de tudo, "práticas sociais que apresentam diferentes significados para participantes, e, portanto, estão sujeitas a mudanças e conflitos". Por isso, segundo os autores, grupos que trabalham de forma colaborativa podem apresentar, por exemplo, grande entusiasmo na parte inicial de levantamento das ideias e no planejamento. No entanto, o seu grau de comprometimento pode diminuir nas atividades de escrita depois de um certo tempo. Podem ocorrer ainda conflitos em relação a possíveis compromissos externos, assumidos por alguns dos membros dos grupos, ou podem ainda ocorrer outras questões difíceis de prever: os objetivos, as estratégias e os papéis assumidos pelos participantes podem, com uma certa frequência, mudar ao longo do projeto (LOWRY et al., 2004). Todavia, mesmo reconhecendo que o trabalho colaborativo de escrita pode envolver, muitas vezes, divergências e conflitos de opiniões, considero que é por meio de muitos desses possíveis embates de ideias e opiniões que se constrói, de fato, conhecimento coletivamente e se pode, por conseguinte, gerar PCE.

Destarte, pode-se afirmar que a colaboração está, desse modo, relacionada à noção de prática social acima apontada, ou seja, é parte de "um fazer num contexto histórico e social que dá estrutura e significado ao que se faz" (WENGER, 1998: 47). Nesse sentido, os participantes, ao se envolverem em PCE, não se isolam para realizar atividades de forma individual - embora isso também possa fazer parte do processo colaborativo de escrita -, mas se

4 Lowry et al. (2004) apontam em seu trabalho que pesquisas sobre a 'escrita colaborativa' nas áreas tecnológicas já vêm ocorrendo há algum tempo. Só recentemente as ciências humanas e sociais têm se interessado pelo assunto.

5 Quando me refiro aos “enfoques", estou chamando a atenção para as especificidades inerentes a cada área, com seus interesses e situações próprios; quanto aos "posicionamentos teóricos”, refiro-me, de forma mais ampla, à visão de pesquisa adotada (estruturalista, cognitivista, sócio-construtivista etc.). 
mantêm engajados numa tarefa compartilhada, que é construída e mantida pelo/ para o grupo como tal. A colaboração e o compartilhamento social daquilo que é entendido pelo grupo como relevante ou necessário se tornam, portanto, fenômenos centrais das PCE.

Tomando, portanto, como base o aporte teórico até aqui delineado, passo, na seção seguinte, para a contextualização e a análise dos dados deste estudo.

\section{CONTEXTUALIZAÇÃO E ANÁLISE DOS DADOS: UM EXEMPLO DE PCE NO CONTEXTO ESCOLAR}

Nesta seção, procuro contextualizar o estudo com base em análises de PCE no contexto escolar que possa mostrar o processo colaborativo de escrita de algumas atividades dos(as) alunos(as) envolvidos(as) nesta pesquisa. Especificamente, trata-se de um breve recorte da minha pesquisa de doutorado, publicada em 2011, em que realizei uma investigação com base na análise de um corpus gerado a partir de um projeto de ensino de um jornal digital escolar que desenvolvi numa escola estadual localizada no município de Campinas - SP, entre os meses de agosto e dezembro de 2008, com um grupo de voluntários composto por dezenove alunos(as) do primeiro e segundo anos do Ensino Médio do período escolar matutino, com idades entre quinze e dezessete anos. O projeto de ensino consistia, basicamente, no trabalho colaborativo dos(as) alunos(as) no processo de produção das matérias a serem expostas no jornal, a partir do uso de duas ferramentas digitais: a conversa instantânea e o correio eletrônico.

Semanalmente, reunia-me com os(as) alunos(as) em uma das salas de aula da escola, onde discutíamos como foi o trabalho dos(as) alunos(as) ao longo da semana anterior e a pauta dos assuntos e notícias a serem abordados no jornal online na semana seguinte. Criamos um site na Internet para divulgação de notícias e os(as) alunos(as) passaram a compor, então, o "corpo editorial" do jornal, que era atualizado semanalmente. Para a realização das várias atividades necessárias para a produção do jornal, os(as) alunos(as) foram agrupados da seguinte forma: 
- Dois alunos(as) eram responsáveis pela criação e manutenção da homepage (diagramação e formatação dos textos, formato e tamanho dos arquivos, lay-out da página, cores, inserção dos conteúdos na página - textos, imagens, sons, vídeos - inserção de links para acesso a outras páginas e ícones para realização de enquetes sobre determinados assuntos com os usuários leitores do jornal);

- O grupo maior (doze alunos) era responsável pela produção textual propriamente dita. Esse grupo de doze alunos(as) foi, por sua vez, subdividido em quatro sub-grupos, cada um com seu respectivo líder;

- Um outro grupo (composto por cinco integrantes, sendo um o líder) era responsável não só por fazer a revisão dos textos, mas também por outros recursos multimodais (vídeos, imagens, sons, fotos etc.) a serem expostos no jornal digital.

Com base nesse projeto de ensino, foi possível gerar os dados empíricos que me possibilitaram, ao longo dos quatro meses de sua vigência na escola, construir o corpus de análise da tese, a partir dos registros gerados de encontros online via conversa instantânea e correio eletrônico entre todos os participantes envolvidos na produção das matérias do jornal.

Para dar conta do processo colaborativo de escrita, fiz uso das atividades colaborativas de escrita (collaborative writing activities), em que se desenrola todo o processo colaborativo de escrita propriamente dito (LOWRY et al., 2004) ${ }^{6}$. Essas atividades, segundo Lowry et al. (2004), envolvem subdivisões que descrevem e compõem cada fase do processo colaborativo de escrita. Tais subdivisões incluem as atividades de: 1) brainstorming $\left.{ }^{7}, 2\right)$ esboço (outlining), 3) rascunho (drafting), 4) revisão inicial (revewing), 5) revisão (revising) e 6) edição (copyediting): 1) brainstorming seria a primeira atividade do processo colaborativo de escrita, em que os membros do grupo basicamente discutem e desenvolvem ideias para construir um determinado texto;

6 Para detalhes mais específicos acerca das atividades colaborativas de escrita, ver Pinheiro (2011b).

$7 \mathrm{Na}$ falta de um termo mais adequado em português e por já ser bastante usado (em inglês) em várias áreas do conhecimento, optei por não traduzir o termo "brainstorming". 
2) o esboço já seria a fase em que se decide em grupo o que será feito com as ideias expostas na atividade de brainstorming e se impõe a direção para a qual o documento a ser elaborado vai seguir, incluindo suas seções e subseções; 3 ) o rascunho já seria propriamente o texto do documento, embora ainda em um estágio incompleto; 4) a revisão inicial corresponde a uma primeira revisão, feita por um dos integrantes do grupo, ou mesmo um editor, que lê o documento e faz algumas observações e correções; 5) a revisão já seria, de fato, a revisão propriamente dita, pois é feita por um pessoa ou grupo específico, que revê novamente o texto e responde aos comentários e observações feitos na revisão inicial, fazendo, portanto, as devidas alterações; e 6) a edição seria, então, a atividade final do processo de escrita, em geral, feita por uma pessoa específica, em que se realizam as mudanças finais no documento e as formatações nele necessárias para o seu acabamento final.

Contudo, devido às limitações deste artigo, o recorte no corpus gerado abarca apenas as atividades de brainstorming e de esboço de texto de um dos subgrupos de alunos(as) responsáveis pela produção das matérias do jornal digital da escola. A escolha por analisar somente essas duas atividades se deu, primeiramente, porque a colaboração entre os participantes nessas atividades é maior, uma vez que ocorrem tanto discussões coletivas iniciais sobre os textos a serem escritos (brainstorming), quanto a própria elaboração em conjunto dos textos em si (esboços). Além disso, ambas as atividades constituem juntas um processo que envolve tanto o uso da conversa instantânea quanto do correio eletrônico.

Ao fazer uso desses elementos das atividades colaborativas de escrita neste trabalho, pretendo, de fato, mostrar como elas se inter-relacionam ao longo do processo colaborativo de escrita, não atuando, portanto, como categorias estanques (EC), mas sim interdependentes, possibilitando, assim, realizar uma análise processual (PCE) da construção da escrita entre os(as) alunos(as).

O objetivo de uma análise processual é também o de possibilitar observar os possíveis progressos que os(as) alunos(as) tiveram ao longo do período em que a pesquisa de campo foi realizada na escola. Para tanto, realizei uma análise que contempla duas partes distintas: na primeira parte, analisei o processo colaborativo de escrita dos(as) alunos(as) na elaboração inicial 
(atividades de brainstorming e esboços) da primeira matéria que inaugurou o jornal online da escola em meados do mês de agosto de 2008, em que os(as) alunos(as) ainda estavam começando a lidar com o trabalho colaborativo de produção textual; na segunda parte, o processo colaborativo de escrita do mesmo subgrupo, realizado no início do mês de novembro de 2008, portanto, quase três meses depois.

Os trabalhos colaborativos a serem analisados foram realizados por Márcia (líder), Roberta e Sérgio ${ }^{8}$. O primeiro trabalho teve início na atividade de brainstorming no dia 16 de agosto de 2008. O tema sugerido pelo subgrupo para essa primeira matéria foi "MEADD leva jovens menores a shoppings de Campinas para brigar", em que os(as) alunos(as) pretendiam escrever uma matéria, discorrendo acerca do uso do site de relacionamento MEA$D D$ para marcar encontros entre jovens em um Shopping de Campinas para brigar. Além dos três alunos(as), houve também a minha participação como mediador da interação (Pesquisador $-P$ ).

\subsection{Primeira parte do processo colaborativo de escrita do subgrupo (16/08/2008): “MEADD leva jovens menores a shoppings de campinas para brigar"}

\subsection{1. atividade de brainstorming ${ }^{10}$ :}

P: gente, pra ficar mais facil, Roberta e Sérgio, escolham cores diferentes pra vocês.

Roberta: ta bom assim??

Sérgio: com e q muda a cor mesmo??

Márcia: uhhh..tá vendo uma figurinha em baixo da onde escreve AB? clica lá

8 Por razões éticas, os nomes dos(as) alunos(as) envolvidos neste estudo foram substituídos por pseudônimos.

9 As matérias "MEADD leva jovens menores a shoppings de Campinas para brigar" e "O negro no Brasil: uma questão de justiça” se encontram publicadas na íntegra na página da Internet do jornal (www.zimbaoonline.tk). Acesso em 21/09/2009.

${ }^{10}$ Não foram feitas quaisquer alterações nas interações realizadas por meio da conversa instantânea e do correio eletrônico expostas neste estudo, mantendo-as, portanto, na íntegra. Além disso, todos os participantes envolvidos assinaram um termo de compromisso no qual me autorizaram a divulgar publicamente suas interações realizadas via conversa instantânea. 
q da pra escolhe a cor

Sérgio: ... valeu achei!!

P: tá ótimo... então, vamos começar?

Roberta: ok, e aí como agente começa?

Márcia: ?? naum sei

P: ok. sem problemas. vamos lá. como vocês vão estão pensando em fazer o texto?

Márcia: então... eu pensei em falar com os meus amigos sobre a proibição nos shoppings

Sérgio: qual e o assunto mesmo??

P: Roberta, fala pro sérgio sobre o tema.

Roberta: ah intao... as pessoa taum marcando MEADD de se encontrar no shoping para brigar

Sérgio: ok. blz.

P: mas como vcs pretendem começar o texto? falando de que?

Roberta: eu to ainda nao sei como começarr

Márcia: falando da proibição dos encontros de meadd dentro do shopping e falando sobre as pessoas menores que naum tem nada aver om isso. mas, também tem q controlar a situação pra naum ter briga, né?

P: ok. muito bom!

Sérgio: eu não sei muito sobre isso, mas vou pesquisa

$P$ : acho que vcs podem começar assim mesmo, falando da proibição... e mostrar a opinião de algumas pessoas sobre isso.. mas acho que seria bom mostrar mesmo os dois lados da moeda no texto.

Márcia: ahan

Roberta: ta bomm

Márcia: ótimo

Roberta: tah bomm

$P$ : e a enquete? O q pensam?

Márcia: a enquete eu ainda num pensei

Roberta: eu pensei... o que vcs achaam da proibiçao das turmas de menores entrar no shopping?

Sérgio: nem eu

$P$ : se vcs pegarem umas entrevistas vai ficar bem legal! 
Roberta: acho que a entrevista vai ficar legal!

P: agora pessoal. Na próxima vez... façam uma pesquisa do assunto antes da nossa conversa. Pra vocês tererm mais ideias sobre o que vão escrever!. Ok? Roberta:ok. pode deixar!

Márcia: ahan

Sérgio: com certeza!

P: beleza. e o video? vão fazer algum?

Roberta: claro!!

Márcia: a Roberta tem bastante amigos para dar entrevistas;

P:ok, então... mais alguma dúvida?

Roberta: nenhuma

Márcia: não

Sérgio: ok

$P$ : bem, gente então é isso. qualquer coisa me mandem um e-maial

Márcia: ok

Sérgio: ok

P: e Márcia, tem que mandar a materia para a revisão até quarta no máximo!

Nessa primeira atividade de escrita (brainstorming), por ser uma atividade em que os(as) alunos(as) interagem em tempo real na conversa instantânea, esperava-se que eles discutissem acerca de uma das matérias que seria publicada no jornal na semana seguinte a essa interação na conversa instantânea. Mais especificamente, essa interação deveria envolver uma discussão entre si sobre o assunto e sobre como pretendiam escrever o texto (de que forma iniciariam o texto, que posicionamentos seriam tomados, se colocariam entrevistas, imagens, fotos ou vídeos etc.).

Essa possibilidade de construção conjunta de significados na interação se torna ainda mais visível na própria estrutura da conversa instantânea, visto que esta apresenta uma estrutura semelhante a uma conversa, embora com uma distribuição de turnos mais equânime entre os participantes. Depois de iniciada, é possível notar que a interação ocorreu sem qualquer sobreposição de vozes ou interrupção na tomada de turnos por parte dos interactantes. Trata-se, portanto, de um tipo de interação em que os alunos, embora estivessem fisicamente distantes uns dos outros, conseguiram, as- 
sim como numa interação face-a-face, interagir entre si de forma síncrona.

Observa-se também que a discussão na conversa instantânea ocorre no nível metacomunicativo, já que o objetivo da interação é justamente o de construir um texto, usando como recurso alguns elementos ou ideias representativas sobre o próprio texto. Nota-se, por exemplo, que, logo no começo do excerto, Roberta e Márcia já levantaram dúvidas através de perguntas sobre o modo como (tipo de linguagem) eles deveriam começar a escrever na interação ("ok, e aí como agente começa?" e "?? naum sei"). Pode-se afirmar, nesse caso, que as dúvidas das alunas assumiram, de fato, um caráter metacomunicativo, visto que, ao questionarem acerca do uso da linguagem em um determinado meio de comunicação digital (a conversa instantânea), os participantes estariam lidando com o uso reflexivo da língua, na tentativa de compreender não apenas como cada participante deveria interagir, ou fazer uso da linguagem, por meio de uma ferramenta digital específica (no caso, a conversa instantânea), mas também num contexto de uso específico (uma conversa por escrito online sobre uma matéria que os alunos estão preparando para o jornal digital da escola), já que, mesmo estando acostumados a conversarem com bastante frequência via conversa instantânea, os(as) alunos(as) poderiam se sentir um tanto inseguros na interação diante de uma outra função para o uso da ferramenta.

Essa possível insegurança em relação ao modo como deveriam interagir na atividade de brainstorming está, outrossim, relacionada ao tipo de interação dessa atividade, que, em geral, não pressupõe necessariamente um planejamento prévio e uma coordenação explícita do que vai ser elaborado. Contudo, por se tratar, sobretudo, do primeiro encontro online que tiveram para discutir sobre a matéria a ser feita para o jornal, os(as) alunos(as) pareciam ainda não saber lidar com essa atividade, já que se trata de sua primeira participação. Isso, por sua vez, está relacionado aos papéis e posicionamentos dos participantes na interação, uma vez que, ao mostrar quem são os interactantes envolvidos no processo colaborativo de escrita, pode-se notar o modo como eles se posicionam sócio-discursivamente em relação uns aos outros nesse processo. Na interação acima, nota-se, por exemplo, que, apesar de ter apresentado uma sugestão inicial para a elaboração do texto, a líder Márcia não foi além disso, limitando-se apenas a acatar as minhas sugestões 
(P). Ao mesmo tempo, ela também pareceu se eximir do seu papel de líder muito provavelmente por insegurança, não em relação ao papel em si, mas em relação ao próprio trabalho de escrita. Roberta, por sua vez, apesar de ter tentado, de alguma forma, participar da discussão, propondo inclusive a pergunta para a enquete da matéria da semana, também não trouxe contribuições expressivas para a produção do texto.

Diante dessa situação, em que os participantes ainda estavam um tanto confusos com essa forma de lidar com a produção escrita, considero o meu papel na interação fundamental para o processo de aprendizagem colaborativa desses(as) alunos(as). Isso porque me posicionei como o moderador da interação, buscando sempre manter o controle da discussão do assunto e promover discussão ao instigar os(as) alunos(as), através de questionamentos, a discutirem sobre o assunto a ser tratado na matéria do jornal.

Dando continuidade às PCE dos participantes, subsequentemente à atividade de brainstorming, vem a atividade de esboço do grupo. Nessa atividade, cada integrante do grupo enviou por correio eletrônico uma parte do texto a ser elaborado, ou mesmo o texto inteiro, para os demais participantes, que poderiam alterá-lo acrescentando alguma parte, ou apenas corrigindo o texto inicial enviado pelo primeiro integrante. Como o subgrupo criou seu próprio grupo de e-mail, quando o texto era enviado pelo terceiro integrante, os demais já haviam recebido e feito (ou não) suas alterações no texto inicial. Por isso, para observar a atividade de esboço do subgrupo, bastou apenas exibir o último documento enviado por algum membro do subgrupo. Na atividade de esboço que analiso a seguir, o último documento foi enviado via correio eletrônico por Sérgio, depois de já ter passado por Roberta (cor vermelha) e por Márcia (cor rosa).

\subsubsection{Atividade de esboço:}

oi pessoal, blz?"11

li o texto e pra mim tá bom!!!

Abrç.

Sérgio.

${ }^{11}$ Para diferenciar os textos (a matéria do jornal) dos comentários feitos no próprio espaço do correio eletrônico sobre os textos, estes últimos serão marcados com fonte em itálico. 
Surge no Brasil, um novo site de relacionamentos, o Meadd. Entretanto um grande problema surgiu por causa desse site, as pessoas estavam se encontrando nos shoppings e estava acontecendo muitas brigas. Por causa desses acontecimentos, alguns shoppings de Campinas foi proibida a entrada de menores de 18 anos nas sextas e nos sábados à noite.

Muitos jovens acham que o que fizeram foram totalmente absurdo, pois,eles estão lá só para conhecerem novas pesssoas e encontrarem amigos.

Outros tem a opinião de que essa proposta é ótimas,pois muitos adolescente e jovens estão matando aula para ir nesses encontros,e correndo o risco de acontecer algo de ruim,porque na maioria das vezes os pais não sabem que eles vão.

Entretanto,os jovens tinham que ter a consciência de que é bom respeitarem lugares públicos e que tem pessoas de família circulado naquele local,e que respeito é a base de tudo.

A atividade de esboço é uma atividade de escrita em que os participantes, de fato, elaboram um texto. Todavia, se o objetivo aqui é, antes de tudo, analisar as PCE como um processo, o ponto central a ser tratado não seria propriamente os possíveis problemas de escrita apresentados pelo subgrupo nessas atividades, mas a transformação das discussões que tiveram durante a atividade de brainstorming em um esboço de texto que atenda ao objetivo geral do subgrupo. Na atividade de esboço, o subgrupo deve, portanto, decidir o que será feito com as ideias expostas na atividade de brainstorming na tentativa de delinear, já na forma de um texto, a direção que o documento a ser elaborado vai seguir.

Nesse sentido, percebe-se que os participantes, ao construírem seus textos, procuraram, de alguma forma, retomar no esboço o assunto que já tinha sido tematizado na atividade de brainstorming ("MEADD leva jovens menores a shoppings de Campinas para brigar"), com base, por sua vez, nas noções anteriores que já haviam sido recontextualizadas na interação via conversa instantânea. Nota-se que o esboço de Márcia, por exemplo, ao se 
referir a supostas opiniões contrárias de jovens, estabeleceu uma relação com a discussão anterior na atividade de brainstorming, porquanto reverberou uma das sugestões feitas para a matéria do subgrupo na conversa instantânea ("e mostrar a opinião de algumas pessoas sobre isso.. mas acho que seria bom mostrar mesmo os dois lados da moeda no texto").

No que diz respeito especificamente à elaboração do texto em si, é possível afirmar que Roberta interveio com a sua parte no documento inicial de base feito por Márcia, ou seja, no momento em que Roberta inseriu suas contribuições, era ela quem estava no controle do texto, ainda que sua intervenção tenha dependido da existência do texto inicial fornecido por Márcia. A principal vantagem de se formar um esboço a partir de um documento inicial, em que já se tem ali um texto base de referência, é que seria mais improvável haver falta de consenso no grupo, proveniente, por exemplo, de algum tipo de sobreposição de ideias distintas de cada integrante. Isso é particularmente importante no caso do trabalho em questão que, por ter sido o primeiro trabalho realizado pelo grupo, poderia apresentar problemas de consenso na equipe.

Se se observar a produção das duas atividades de escrita do ponto de vista do papel e dos posicionamentos dos participantes envolvidos, é possível notar que os objetivos da atividade de esboço, assim como de brainstorming, ainda não estavam claros para os integrantes. Isso porque, embora os(as) alunos(as) que aqui participaram sejam os mesmos três alunos que fazem parte do subgrupo - e que participaram da interação na conversa instantânea analisada na seção anterior -, pode-se dizer que Sérgio, por exemplo, se mostrou ausente na atividade de esboço, pois não trouxe contribuição alguma para os dois primeiros esboços, limitando-se apenas a comentar na mensagem do correio eletrônico que achou o texto bom ("li o texto e pra mim tá bom!!!"), na tentativa de justificar sua não intervenção nos textos das colegas de grupo.

É preciso lembrar que a produção do texto em questão durante a atividade de esboço, assim como a maioria das produções textuais realizadas pelos participantes através do correio eletrônico, se constitui, de alguma forma, a partir da discussão que os interactantes envolvidos tiveram anteriormente via conversa instantânea. Isso quer dizer que os posicionamentos discursivos 
assumidos pelos participantes, tanto em relação ao assunto tratado quanto em relação uns aos outros (posição de liderança ou de retração, por exemplo), na discussão anterior feita na conversa instantânea podem ter tido, de fato, influência considerável na produção do texto via correio eletrônico.

Nota-se também que, diferentemente da atividade de brainstorming, não há a minha intervenção nas interações por correio eletrônico, visto que a atividade de esboço pressupõe um grau maior de autonomia e responsabilidade dos(as) alunos(as) na produção do texto a ser publicado no jornal. E, mesmo sem uma cobrança formal da líder Márcia em relação ao atraso na entrega dos esboços por parte dos demais integrantes, já que ela mesma se atrasou, pode-se dizer que o grupo conseguiu cumprir seu papel de elaborar um texto para se transformar em uma das matérias do jornal, ainda que sem a participação de um dos membros (Sérgio) e sem uma revisão prévia da líder.

Por ser uma atividade de escrita do texto propriamente dito, e não mais de discussão sobre o texto, os esboços são feitos em tempos diferentes, isto é, por meio de uma ferramenta digital assíncrona: o correio eletrônico. Essa natureza assíncrona permite enviar textos para que sejam armazenados e depois respondidos, o que torna o correio eletrônico uma ferramenta mais adequada para justamente lidar com problemas complexos de PCE.

Como o trabalho nessas atividades é feito de forma assíncrona e todos os membros do grupo podem ver, através do grupo de e-mail criado, o que, quando e como cada participante elaborou seu texto, pode-se afirmar que esse trabalho se torna um meio através do qual os integrantes constroem sua consciência não apenas em relação ao que cada um está fazendo e de que forma, mas também no que diz respeito aos posicionamentos, responsabilidades, grau de envolvimento, atenção e nível de comprometimento de cada participante do subgrupo, o que é deve ser um dos motes na construção de PCE. Assim, apesar de não terem verbalizado, Márcia e Roberta, por exemplo, tinham consciência da falta de envolvimento de Sérgio nas atividades de escrita do grupo. 


\subsection{Segunda parte do processo colaborativo de escrita do subgrupo (07/11/2008): “O negro no Brasil: uma questão de justiça"}

Conforme anunciei acima, a segunda parte do processo colaborativo de escrita ocorreu a partir do dia 07 de novembro de 2008, portanto quase três meses depois do início da pesquisa de campo na escola, com os mesmos participantes do jornal (Márcia, Roberta e Sérgio), envolvendo as mesmas atividades (brainstorming e esboço). Com efeito, ao proceder com esse tipo de análise, que inclui um intervalo de quase três meses de experiência, tenho como objetivo precípuo observar e avaliar os possíveis progressos do grupo no que diz respeito às PCE como um todo, seja na habilidade com os usos das ferramentas e recursos digitais, seja na relação com as tarefas do jornal e com os próprios participantes envolvidos.

\subsubsection{Atividade de brainstorming:}

P: E aí, pessoal, seguinte...

$P$ : então o que vcs estão pensando sobre o texto do negro no Brasil?

Roberta: entaum..

Márcia: será que falar...

Márcia: tipo da realidade que o negro sofri no Brasil?

Sérgio: eh. falar dos preconceitos que sofre

Márcia: eu tava vendo aqui nos sites da net coisa de salario. tipo o negro ganha menos que o branco e que a situação é muito injusta!

Roberta: acho boa a ideia! podia mostrar que eles fazem a mesma coisa mas ganha menos.

P: isso é legal!

$P$ : mas como vcs vão mostrar isso?

Sérgio: ah pode colocar tipo...uma pesquisa mostrado...

Sérgio: comparando mecado de trabalho e o negro...

Márcia: pesquisa é bom!

Márcia: podia tbm colocar uma foto do negro no mercado de trabalho.

Roberta: ? não entendi... 
Roberta: a ta. ok

Roberta:eu tava lendo aqui na net do primero ministro negro do STJ. Acho q podia fala disso...

$P$ : acho uma ótima ideia!

Márcia: vamos sim. mto bom!!!!

Sérgio: vai fca bom sim!!

Roberta: entaum... vê aí o http://ultimainstancia.uol.com.br/noticia/56224.shtml

Márcia: acho q podia dividi.

$P$ : como assim, Márcia?

Márcia: tipo.. a beta podia ve sobre esse negocio do ministro... eo sergio via a pesquisa do mercado de trabalho???

$P$ : então Roberta e sérgio, o que vcs acham?

Roberta: acho q fica bom assim!!!

Sérgio: sem problemas!

Márcia: entaum vou escrever isso e mando pra vcs verem aí vcs colocam a parte de vcs. blz??

Sérgio: blz.. vou ver o q eu acho aqui tb

Roberta: manda então que eu vou ver

Márcia: acho q vai ficar mais legal. vou escreve o q eu pesquisei aqui e depois mando p vcs. E o que vcs acharem mandem pra mi. tem até 5 feira pra mandar pra revisão

P: Isso aí, Márcia!! bem lembrado! não esqueçam de mandar a matéria no prazo certinho!! Até quinta

Nesta atividade de brainstorming nota-se que, do mesmo modo que na anterior, a discussão entre os interactantes ocorre no nível metacomunicativo, visto que o objetivo da interação é justamente o de construir um texto, usando como recurso alguns elementos ou ideias representativas sobre o próprio texto. No entanto, é possível perceber que, diferentemente da primeira atividade de brainstorming do grupo, a troca de turnos entre os interactantes aqui ocorre de forma bem mais simétrica e distribuída, uma vez que todos os três alunos trazem contribuições para o processo de produção do texto a ser publicado no jornal. Isso ajuda a corroborar a ideia de que a conversa instantânea pode, de fato, contribuir para uma participação mais 
equânime e também revelar posicionamentos sociointeracionais relevantes para o trabalho em grupo dos discentes.

Com efeito, na interação acima, por ser mais equânime e distribuída, é possível perceber que os participantes não apenas trouxeram suas sugestões e dúvidas em tempo real - ao tratar do tema da discussão ("O negro no Brasil, uma questão de justiça”) -, mas também reagiram e se ajustaram às contribuições de cada um do grupo, o que, no caso, envolveu, de alguma forma, consenso e reflexão sobre a questão. Percebe-se, por exemplo, que, depois de Márcia ter dado uma sugestão inicial ("tipo da realidade que o negro sofri no Brasil?”), Roberta e Sérgio trouxeram também suas ideias para a discussão. Por isso, é possível notar que, diferentemente da primeira atividade de brainstorming, os(as) alunos(as) já estão, de fato, mais acostumados - e, por isso, mais envolvidos, com essa estratégia colaborativa de escrita.

$\mathrm{Na}$ interação acima, embora os papéis atribuídos aos participantes envolvidos sejam os mesmos da primeira interação (pesquisador (P), Márcia (a líder), Roberta e Sérgio), os posicionamentos assumidos já apresentaram diferenças consideráveis. No meu caso, por exemplo, apesar de ainda me posicionar como o moderador da interação, meu papel é visivelmente reduzido se comparado com a primeira interação realizada.

Na conversa em questão, o que se torna, de fato, interessante é que, entre os três participantes, percebe-se que a líder Márcia é quem mais vezes tomou o turno. Ao fazer isso, Márcia chegou a assumir, inclusive, o papel de facilitador por duas vezes: na primeira, ela elogia as ideias de Sérgio e Roberta (“pesquisa é bom!" e "vamos sim. mto bom!!!!”); na segunda vez, Márcia trouxe sugestões para a discussão, na tentativa de dar um direcionamento ao texto a ser elaborado pelo grupo, que foram ratificadas e complementadas por ideias de Roberta e de Sérgio. Além disso, Márcia ainda trouxe sugestões também para o próprio modo como o grupo poderia continuar a atividade de rascunho. No final da interação, depois de dizer o que faria em relação à sua parte, ela ainda advertiu seus colegas de que o texto deveria ficar pronto até a quinta-feira seguinte para que fosse enviado para a equipe da revisão ("acho q vai ficar mais legal. vou escreve o q eu pesquisei aqui e depois mando p vcs. E o que vcs acharem mandem pra mi. tem até 5 feira pra mandar pra revisão"). 
É possível afirmar que tais posicionamentos discursivos de Márcia são corroborados por uma certa relação de poder que existe entre eles. Isso porque, muito embora a interação entre os participantes tenha se constituído, em princípio, de forma simétrica, Márcia, por ser a líder do grupo, era a responsável por enviar os textos produzidos à equipe de revisão, o que a posicionava, pelo menos em determinados momentos, como alguém com maior poder de decisão e opinião no grupo.

Roberta e Sérgio, por sua vez, ao terem trazido também suas sugestões para a discussão, pareceram, do mesmo modo, mais familiarizados com o trabalho. Isso os torna não apenas mais autoconscientes e auto-suficientes em relação ao uso da conversa instantânea como ferramenta de apoio às suas atividades colaborativas de escrita, mas também em relação aos seus papéis e posicionamentos ao longo da atividade.

Por fim, é possível ainda notar na interação acima que Márcia, ao ter começado a tratar com os demais participantes sobre o tema da "realidade do negro no Brasil”, fez menção à questão salarial entre negros e brancos que ela teria pesquisado em sites da Internet. No segundo exemplo, foi Roberta quem fez menção à Internet para sugerir tratar da escolha do primeiro ministro negro do STJ, mencionado, inclusive a fonte da informação ("entaum... vê aí o http://ultimainstancia.uol.com.br/noticia/56224.shtml"). Em ambos os casos, tanto Márcia quanto Roberta trouxeram discursos de outros contextos (de outros textos da Internet) para ser recontextualizados na situação discursiva na qual estavam engajadas. E - o mais interessante - é que elas pareceram ter aprendido que o fato de mencionar textos da Internet que corroboram seus pontos de vista é uma maneira de legitimar seu posicionamento discursivo - e seu texto - perante os demais interactantes.

No desfecho da interação, percebe-se que os alunos conseguiram não somente chegar a um consenso, conforme foi mostrado acima, quanto ao modo como o texto seria construído, mas conseguiram, sobretudo, apontar para a continuidade do processo de produção do texto no qual estavam engajados, ao se remeterem, depois de terem realizado uma discussão geral sobre o assunto, à atividade posterior de elaboração do texto (esboço), na qual eles pretendiam concluir a matéria da semana. Com efeito, isso contribui para corroborar a ideia de que, mesmo estando bem acostumados a usar a conversa instantânea para outros fins (bate-papo entre os amigos, por 
exemplo), os(as) alunos(as) parecem, de fato, ter reconhecido que o modo como devem fazer uso da linguagem ao usar essa ferramenta digital depende sobremaneira da situcionalidade da própria escrita (sobre o que estão escrevendo, para quê, para quem, com que intenção/ objetivo etc.); e isso passa, necessariamente, pelo uso reflexivo da linguagem.

\subsection{2. atividade de esboço:}

\section{Oigente,}

Achei q a parte de vcs ficou boa. Coloqueimais uma parte no final para fechar o texto. Vejam aí.

Bjo,

Márcia.

\section{O NEGRO NO BRASIL, UMA QUESTÃO DE JUSTIÇA}

O povo brasileiro tem que saber da realidade do negro no Brasil. A pessoa negra sofre vários tipos de preconceito, mas tem um que a maioria da população desconhece que é que o negro tem o salário menor que um branco, trabalhando no mesmo cargo em uma mesma empresa. A desigualdade ainda existe. Depois de tantos anos de abolição da escravidão a desigualdade racial continua no mecado de trabalho. A presença de negros é muito maior em trabalhos que paga salários mais baixos. Por exemplo, numa pesquisa do IBGE, a renda média de um trabalhador branco, de R $\$ 1.096$ mensais, é 105\% maior do que a de um negro (fonte: http://www.afrobras.org.br/index. php?option $=$ com content $\&$ task $=$ view\&id $=295 \&$ Itemid $=2$ )

A desigualdade ainda é muito grande, mas nós não podemos e não somos a favor desse tipo de situação. Devemos lutar para que o negro tem os mesmos direitos dos brancos, pois eles fizeram parte da história do Brasil e devemos respeito a eles. Mas uma notícia boa é que com o passar do tempo essa situação vem mudando. 
Este mês foi eleito pelo STJ (Superior Tribunal de Justiça) elegeu o primeiro ministro negro da história do Brasil. Cada vez mais as pessoas negras estão ganhando espaço no mercado de trabalho e está ganhando o devido respeito que merecem.

O mais engraçado é que nós brasileiros sabemos da história do Brasil, o negro que veio para cá e dos índios que viviam aqui, é quase impossível um brasileiro que não tenha um parente descendente de negro ou índio por mais que ele saiba que é descendente de um país europeu.

Temos que continuar trabalhando para que o Brasil seja um país justo, que tenha igualdade, devemos lutar para que o negro possa ganhar o mesmo que o branco, que ele possa ter as mesmas oportunidades, que possa ganhar aquilo que é justo, só assim construiremos um país melhor. E não só por isso que devemos lutar, expressar nossa opinião, tem muitas outras coisas que o nosso país deixa a desejar e quem faz o nosso país somos nós mesmos.

\section{Enquete: Você acha que o negro no Brasil ainda sofre muito preconceito?}

De início, já é possível perceber que aqui, diferentemente da primeira atividade de esboço analisada acima, todos os três integrantes do subgrupo participaram da atividade de esboço, uma vez que os três trouxeram, de fato, suas contribuições para a construção do texto. Nota-se ainda que o trabalho colaborativo desta vez ocorre de forma mais complexa se comparada também com a primeira atividade de esboço analisada. Aqui, observa-se que a construção do esboço não se deu exatamente em função de um texto inicial a partir do qual os demais interactantes inseriram suas partes, mas em função da divisão do trabalho de divisão de tarefas pela própria equipe em determinadas unidades para que cada membro trabalhasse em paralelo. Com efeito, essa divisão do trabalho já havia ocorrido na atividade de brainstorming, em que Márcia sugeriu dividir as tarefas ("tipo.. a beta podia ve sobre esse negocio do ministro... eo sergio via a pesquisa do mercado de trabalho???"). Nesse caso, é possível afirmar que esse modo de trabalhar pressupõe mais 
autonomia aos participantes do grupo, uma vez que a discussão anterior via conversa instantânea os permitiu a atribuição de tarefas e responsabilidades sobre a produção do texto para cada integrante.

Em relação aos papéis e posicionamentos assumidos pelos participantes, primeiramente, é preciso ressaltar novamente que, diferentemente da primeira atividade de esboço analisada, Márcia, Roberta e Sérgio, de fato, participaram aqui. Isso porque Sérgio, que nos primeiros trabalhos do jornal, ainda não se fazia muito presente, passou a participar mais das atividades de escrita. Márcia, por sua vez, que, no primeiro trabalho, ainda parecia não estar ciente de suas atribuições como líder, ao longo desse período de quase três meses de trabalho colaborativo de escrita, pareceu, de fato, mais consciente de seu papel, assumindo, portanto, posicionamentos discursivos mais condizentes com sua função no subgrupo. Por exemplo, além de ter tomado a frente da interação na atividade de brainstorming, ela ainda desempenhou igualmente seu papel de líder ao ter mostrado autonomia em inserir mais uma parte final no texto já previamente elaborado pelo subgrupo, o que, diferentemente da primeira atividade de esboço realizada, demonstrou também uma preocupação com a qualidade do texto a ser enviado para publicação.

Por fim, ainda é possível chamar a atenção para o fato de os participantes, ao construírem seus textos, terem procurado, de alguma forma, promover um diálogo com algum outro discurso, retirado de seu ambiente interacional, recontextualizando-o junto com o seu texto em um novo contexto. Primeiramente, pode-se afirmar que os interactantes, de fato, retomaram em seu texto o assunto que já tinha sido tematizado na discussão anterior na conversa instantânea: "A realidade do negro no Brasil". Isso se evidenciou a partir das partes do texto de cada participante, que, ao longo de todo o texto, trouxeram elementos da discussão realizada na conversa instantânea. Observa-se, por exemplo, que o ponto central do texto - a situação injusta do negro no mercado de trabalho -, tematizado na conversa instantânea, foi tratado pelos participantes a partir de três questões: a injustiça salarial, a taxa de desemprego e a presença maior de negros em trabalhos cujos salários são menores quando comparados com os brancos. As duas primeiras questões foram levantadas por Márcia e a terceira questão foi abordada por 
Sérgio, quando mostrou que a desigualdade racial se verifica no mercado de trabalho, em que os negros desempenham funções remuneradas com valores mais baixos.

\section{CONCLUSÃO}

Ao mostrar como se constituem as PCE, com base em uma discussão teórica e em dados empíricos, meu objetivo não foi apenas o de diferenciá-las do que comumente vem sendo chamado de EC, mas sobretudo o de pensá-las à luz do contexto escolar. Nesse sentido, procurei, em um primeiro momento, deixar claro o que entendo por colaboração, não fazendo uma diferenciação contrastiva e estanque com a cooperação, mas tentando estabelecer uma relação complementar por meio da interface entre ambos os conceitos.

Essa visão complementar entre colaboração e cooperação está na base da noção do que venho chamando de PCE, cujo foco, ao constrário da EC, não está no resultado final - embora este seja também importante - mas no processo colaborativo de construção de sentidos, que se centra na inter-relação entre os participantes envolvidos, o que envolve a mediação entre pessoas para a construção conjunta (incluindo também trabalhos cooperativos de escrita) de um determinado objeto. Nesse caso, pode-se dizer, portanto, que a colaboração entre os participantes já se faz presente antes mesmo da própria produção textual, o que atribui, conforme apontei anteriormente, o caráter colaborativo mais às práticas (discussão sobre os assuntos das matérias e elaboração de esboços via conversa instantânea e correio eletrônico) do que à própria escrita em si, justificando-se, assim, o uso do termo "Práticas colaborativas de escrita" (PCE).

Para explorar, então, a construção de PCE, propus uma investigação de cunho empírico com um grupo de alunos(as) na elaboração de textos para um jornal digital escolar, na tentativa de mostrar como essas práticas de escrita se inter-relacionam ao longo do processo colaborativo de escrita. Mesmo se tratando de um recorte no processo como um todo, foi possível notar que as atividades elencadas para a análise neste estudo, que envolvem as 
atividade de discussão inicial sobre os textos (brainstorming) e a elaboração dos textos (esboços), se constituem, de fato, como um processo colaborativo de escrita, pois não atuam como categorias estanques, mas sim interdependentes, possibilitando, desse modo, realizar uma análise processual, e não apenas do produto final, das PCE dos(as) alunos(as).

Pensando especificamente na escola, e em todas as suas atividades tradicionais de produção textual que, em geral, estão longe de promover um trabalho colaborativo entre discentes, considero que aquilo que se busca alcançar por meio de PCE precisa ser parte integrante - e, sobretudo, estimulante - do processo, já que a "escrita pela escrita em si" talvez não os motive a escrever. Nesse sentido, a exploração da internet pode trazer, de fato, importantes contribuições ao trabalho coletivo, às trocas afetivas e à construção social de conhecimento, o que possibilita vislumbrar, conforme disse anteriormente, um novo modus operandi para a constituição de PCE.

Para que isso ocorra, é preciso que a escola pare de fazer pensar que a escrita se constitui como uma prática “endógena”, cuja preocupação está em torná-la fruto de um trabalho formal voltado exclusivamente para o âmbito da sala de aula, como bem exemplificam as famosas "redações escolares", que, além de exigirem temas, em geral, desinteressantes para os alunos, têm apenas como remetente (público-alvo) o próprio professor, que, por sua vez, está muito mais interessado em avaliá-las com base nos "erros" ortográficos e gramaticais do que propriamente no processo de criação dos alunos.

Com efeito, a proposta de um jornal digital escolar coletivo, como a aqui mostrada, é algo que pode, de fato, tornar a escrita uma prática "exógena" reconhecendo, de fato, sua importância fora do âmbito escolar - e, por isso, ser algo estimulante e desafiador para alunos e professores, visto que a publicação em um jornal - sobretudo na Internet - disponibiliza aos alunos um espaço público para que eles possam discutir abertamente questões de seu interesse que, em geral, são escamoteadas no contexto escolar tradicional.

Destarte, pode-se dizer que as PCE se constituem aqui como processos de aprendizagem, que, são sempre mediados por artefatos sociais, históricos e culturais diversos. Portanto, pensando de forma mais ampla, é possível afirmar que a internet, como um desses artefatos, propicia muitas ferramentas digitais que podem funcionar como instrumentos de mediação e contribuir 
para atividades de produção textual de uma forma que faça com que alunos e professores possam ter tanto a possibilidade de se tornar autores - no exemplo que propus, escritores de um jornal, que veem seus trabalhos divulgados (e até reconhecidos) -, quanto a oportunidade de se engajar em atividades colaborativas de escrita efetiva no contexto escolar.

\section{REFERÊNCIAS BIBLIOGRÁFICAS}

ALLEN, N. J.; ATKINSON, D.; MORGAN. What experienced collaborators say about collaborative writing. Journal of Business and Technical Communication. p.70-90, 1997. Disponível em: http://rel.sagepub.com/ content/41/1/18.full.pdf+html. Acesso em: 11 maio 2008.

BARKLEY, E.; CROSS, K. P.; MAJOR, C. H.. Collaborative Learning Techniques: A Handbook for College Faculty. San Francisco: Jossey-Bass, 2005.

BECK, E.; BELLOTTI, V. M. Informed opportunism as strategy: Supporting coordination in distributed collaborative writing. Paper presented at the Third European Conference on Computer Supported Cooperative Work, Milan, Italy. 1993. Disponível em: www.ecscw.org/1993/16.pdf. Acesso em: 19 jan. 2008.

BELINTANE, C. O cyberaluno. Coleção memória da pedagogia, n. 6: Educação no Século XXI: perspectivas e tendências, 2006, p. 87-97. Rio de Janeiro: Relume Dumar; Ediouro; São Paulo: Segmento-Duetto.

BRNA, P. Modelos de colaboração. In: Revista Brasileira de Informática e Educação, 3, p. 1-15, 1998. Disponível em: www.sbc.org.br/bibliotecadigital/download.php? paper=900. Acesso em: 10 fev. 2009.

CASTELLS, Manuel. A sociedade em rede. In: A era da informação: economia, sociedade e cultura. V 1, 8. ed. São Paulo: Paz e Terra, 2005. 
CHARTIER, R. Os desafios da Escrita. Trad. Fulvia M. L. Moretto. São Paulo: Editora da UNESP. 2002.

COLLIS, B. Cooperative Learning and CSCW: Research Perspectives for Internetworked Educational Environments. In: FIP WORKING GROUP 3.3- Working Conference Lessons from Learning. Archamps, França, 1993. COMEAUX, P. Communication and Collaboration in the Online Classroom: Examples and Applications. Bolton: Anker Publishing Company Inc, 2002.

GREENBERG, S.; GUTWIN, C.; COCKBURN, A. Using distortion-oriented displays to support workspace awareness (Technical report). Calgary, Canada: University of Calgary, 1996. Disponível: www. citeseerx.ist.psu.edu/viewdoc/ download?doi=10.1.1.124.pdf. Acesso em: 22 fev. 2008.

GROSZ, B.J. Collaborative systems. AI Magazine, 17 (2), p. 67-85, 1996. Disponível em: http://www.groupware-patterns.org. Acesso em: 22 mar. 2009.

HENRI, F; LUNDGREN-CAYROL, K. Apprentissage collaboratif à distance. Pour comprendre et concevoir les environnements d'apprentissage virtuels. Saite-Foy: Presses de l'Univertité du Québec. 2001.

HILTZ, S. R.; BENBUNAN-FICH, R. Supporting Collaborative Learning in Asynchrnous Learning Networks. In: UNESCO/OPEN UNIVERSITY SYMPOSIUM ON VIRTUAL LEARNING ENVIRONMENTS AND THE ROLE OF THE TEACHER, 1997. Disponível em: http://web.njit.edu/ hiltz/ CRProject/unesco.htm. Acesso em: 12 set. 2009.

HORTON, M.; ROGERS, P.; AUSTIN, L.; MCCORMICK, M. Exploring the impact of face-to-face collaborative technology on group writing. Journal of Management Information Systems, 8 (3), 27-48, 1991. Disponível em: http:// www.jstor.org/pss/40398006. Acesso em: 23 fev. 2008.

IBIAPINA, I. M. L. M. Formação de professores. Texto e Contexto (Org). Belo Horizonte: Autêntica, 2008. 
LAROCQUE, D.; FAUCON, N. Me, Myself and ... You?. Collaborative Learning: Why Bother. TEACHING IN THE COMMUNITY COLLEGES ONLINE CONFERENCE - Trends and issues in online instruction. Toronto, v. 1-3, 1997. Disponível em: http://leahi.kcc.hawaii.edu/org/tcc-conf/pres/larocque.html. Acesso em: 22 mar. 2009.

LIBERALLI, F. C. Cadeia Criativa: a Argumentação na Produção de Significados Compartilhados. Mimeo. 2007.

LOWRY, P.; CURTIS, A.; LOWRY, M. Building a taxonomy and nomenclature of collaborative writing to improve interdisciplinary research and practice. Journal of Business Communication, 41(1), 66-99, 2004. Disponível em: http://job.sagepub.com/cgi/reprint/41/1/66. Acesso em: 19 fev. 2009.

LOWRY, P. B.; NUNAMAKER JR., J. F. Using internet-Based, Distributed Collaborative Writing Tools to Improve Coordination and Group Awareness in Writing Teams. IEEE Transactions on professional communication, vol. 46, n. 4, 2003. Disponível em: http://ieeexplore.ieee.org/xpl/freeabs_all. jsp?arnumber=1226129. Acesso em: 11 jul. 2009.

MACAULAY, B. A.; GONZALES, V. G. Enhancing the collaborative/cooperative learning experience: A guide for faculty development. Workshop presented at the AAHE NATIONAL CONFERENCE ON HIGHER EDUCATION, Chicago, IL. 1996. Disponível em: http://www.everettcc.edu/uploadedFiles/Faculty_Staff/TLC/Collaborative_Learning/2IDEApaper.pdf. Acesso em: 12 fev. 2009.

MAGALHÃES, M. C.; FIDALGO, S.S. Critical collaborative research: focus on the meaning of collaboration and on mediational tools. In: Revista Brasileira de Linguística Aplicada, Belo Horizonte. v. 10, n. 3, p. 773-797, 2010.

MCINNERNEY, J. M.; ROBERTS, T. Collaboration or Cooperation? In: ROBERTS, T. (Org.). Online Collaborative Learning: Theory and Practice. Hershey: Information Science Publishing, 2004. 
MERCER, N. The quality of talk in children's collaborative activity in the classroom. In: Learning and Instruction, 6, p. 359-379. 1996. Disponível em: http:// www.sciencedirect.com/science?_ob=MImg\&_imagekey=B6VFW-2\&_ cdi=6021\&_user=686415\&_orig=search\&_coverDate=12\%2F31\%2F1996\&_ $\mathrm{sk}=999939995 \& v i e w=c \& w c h p=d G L b V z b-4937348 \& i e=/$ sdarticle.pdf. Acesso em: 11 mar. 2009.

O'REILLY, T. What is Web 2.0?: Design patterns and business models for the next generation of software, 2005. Disponível em: oreillynet.com/pub/a/ oreilly/tim/news/2005/09/30/what-is-web-20.html. Acesso em: 4 abr. 2009.

PANITZ, T. A definition of collaborative vs cooperative learning, 1996. Disponível em: http://www.lgu.ac.uk/deliberations/collab.learning/panitz2. html. Acesso em: 25 jul. 2008.

PINHEIRO, P. A. A escrita colaborativa por meio do uso de ferramentas digitais: ressignificando a produção textual no contexto escolar. In: Calidoscópio. Vol. 9, n. 3, p. 226-239, set/dez 2011a. Disponível em: <http://revistas.unisinos.br/index.php/calidoscopio/article/view/ cld.2011.93.07/557>. Acesso em: 12 nov.2013.

PINHEIRO, P. A. Práticas colaborativas de escrita por meio de ferramentas da internet: ressignificando a produção textual na escola. Tese (Doutorado, Instituto de Estudos da Linguagem), Universidade Estadual de Campinas. Campinas, 2011b.

SCHELLENS, T.; VAN KEER, H.; WEVER, B.; VALCKE, M. Scripting by assigning roles: Does it improve knowledge construction in asynchronous discussion groups?. In: Computer-Supported Collaborative Learning, 2, p. 225-246. 2007. Disponível em: http://www.springerlink.com/content/ml86558v1701335p/fulltext.pdf. Acesso em 12 jan. 2009.

STAHL, G.; HESSE, F. Building knowledge in the classroom, building knowledge in the CSCL community. Computer-Supported Collaborative Learning, 
1, p.163-165. 2006. Disponível em: http://ijcscl.org/_preprints/volume1_issue2/stahl_hesse_1_2.pdf. Acesso em 16 dez. 2008.

STEGMANN, k.; WEINBERGER, A; FISCHER, F. Facilitating argumentative knowledge construction with computer-supported collaboration scripts. Computer-Supported Collaborative Learning, 2, p. 421-447. 2007. Disponível em: http://www.springerlink.com/content/w2377h687j3752n2/fulltext. pdf. Acesso em 09 jan. 2009.

WENGER, E. Communities of practice: Learning, meaning, and identity. Cambridge, (UK): Cambridge University Press, 1998.

WINER, M.; RAY, K. Collaboration Handbook: Creating, Sustaining and Enjoying the Journey. Amherst: Amherst H. Wilder Foundation, 1994. 
